\title{
CONTRAPOSICIÓN ENTRE IMAGEN Y NATURALEZA A TRAVÉS DEL MUNDO DEL TRABAJADOR Y EL MUNDO DEL BURGUÉS EN EL PENSAMIENTO DE ERNST JÜNGER
}

\author{
Comparison Between Image and Nature Throughout the Bourgeois World \\ and the Worker World on Ernst Jünger Thought
}

Guillermo Aguirre

Universidad Complutense de Madrid

guillermo-aguirre@hotmail.com

Fecha de recepción: 8-I-2013

Fecha de aceptación: 22-III-2013

Resumen: La conciencia de que el ser humano no es sino mero representante de una voluntad absoluta, el Espíritu de los tiempos, empujó a Ernst Jünger a la realización de una serie de reflexiones en torno a la imagen donde trataría de ofrecer una mirada reveladora del papel del hombre en la historia. De acuerdo con Jünger, sólo convirtiéndose en sujeto creador el individuo sería capaz de escapar del devenir trágico. Con este fin el autor elaborará un conjunto de escritos guiado por la pretensión de capturar al hombre ataviado con su traje de representación. De este modo, el logrado desenmascaramiento de una falsa realidad invierte el rol usual de la técnica, haciendo de ella instrumento liberador de destinos.

A lo largo de estas páginas estudiaremos esta doble faz de la técnica tomando como guía los presupuestos expuestos por Jünger desde su experiencia como hombre de acción y de observación a un mismo tiempo.

Palabras clave: Jünger, imagen, trabajador, guerra, Espíritu de los tiempos.

AвSTRACT: The awareness that human being is just a puppet of the Spirit of the times, led Ernst Jünger to the creation of a number of reflections around image. Along these reflections, Jünger sought to offer a penetrating insight into the role of mankind in the history. Under Jünger, only as a creator subject human being can escape the historical tragic spirit. To 
this end, the author will write a series of texts with the desire to capture man as an actor of the history -not as a creator of this latter. Thus, contrary to its natural trend, technique is able to lead the human being towards freedom.

This paper will study the double face of technical development using the thoughts of Ernst Jünger -action and thought man at the same time- as a guide.

Keywords: Jünger, image, worker, war, Spirit of the times.

Norton Cru, excombatiente de la Primera Guerra Mundial, a la hora de referirse a esta última tal y como es mostrada por «la historia militar, las novelas y el periodismo según los discursos oficiales y patrióticos» (Jünger: 2005: 20), mencionará el empleo falso, intencionado e interesado, que del lenguaje realizaron dichos medios en aquello que consistía en una

guerra «atlética, deportiva y heroica según unos, u odioso asesinato, matanza recíproca cometida por civilizados embrutecimientos por el alcohol o el éter, borrachos de carnicería y embadurnados de sangre, según los otros» (Jünger: 2005: 20).

Lo cierto es que, de acuerdo con Jünger, tras la Gran Guerra un mundo anquilosado en la seguridad, una organización social propiamente burguesa, había llegado a su fin, sucediéndole ahora una civilización dada a recuperar sus pulsiones primarias, entregada al goce de la naturaleza, por una parte, y por la otra al desarrollo de una técnica que avanzaba con resuelta determinación, sin consideración alguna frente a aquellos rasgos de humanidad que paralelamente trataban de imponer sus ya escasos derechos en la vida del individuo.

Al término de la Primera Guerra Mundial, la relación del hombre con su mundo, dada la confusión provocada como consecuencia del término de un ciclo y el inicio del siguiente, requería ante todo de nuevos medios de representación, demandaba la sustitución de un lenguaje sofisticado y rico en argucias por otro llamado a mostrar una visión alejada de los acontecimientos, aséptica, desvinculada del individuo y, en mayor medida, instantánea. Jünger se referirá a este movimiento de traslación como un desvío hacia el "ámbito del informe objetivo de sucesos» (Jünger: 2005: 27). El artista, integrado ahora en la vida activa, se adentraba en el mundo de los acontecimientos ofreciendo una mirada personal al margen de aquella otra unidireccional y masificada, toda vez que cuanto va aconteciendo en torno suyo obedece a la perspectiva ofrecida desde una cosmovisión tecnificada en sumo grado. Por todo ello, ante una progresiva imposición del proceso de deshumanización, dadas las pocas armas con que el ser humano podía enfrentarse al elemento fáustico, sólo un adecuado incremento de fuerzas primarias posibilitaría la lograda resolución de esta colisión de órdenes reguladores del espíritu humano. 
Esta doble tendencia quedaría reflejada a través del conjunto de unas artes que suministrarían una ingente cantidad de imágenes y mensajes de extremo calado entre la población, adoptando un rol decididamente implicado, ya a favor, ya manifiestamente en contra, de cuanto constituirá el desarrollo del mundo moderno. Frente a una tendencia precedente de adormecimiento general, de peligrosa despreocupación por parte del fenómeno estético respecto del entramado social, el artista nuevamente comenzaba a caminar codo con codo con la realidad, junto al soldado que marchaba al frente, participando, en definitiva, con su deserción del panteón de las divinidades, de una vida bulliciosa que daba rienda suelta a unos desatados instintos primarios, a un afán de emoción y, lo que es más importante, a la necesidad de sentirse partícipe e incluso poseedor del control de los fenómenos sociales.

Por todo ello, a la sensación de decaimiento con que había comenzado el siglo, le sucedería una nueva conciencia de nacimiento propiciada por el desarrollo de la técnica. En consecuencia, como ya hemos mencionado, ese deseo de novedad, esa misma tecnificación, se llevaría por delante una larga serie de valores largamente cultivados a lo largo de los siglos, valores que, en último extremo, constituían el único elemento de canalización de un afán devorador a cuyo ansia el individuo se comenzaba a ver sometido dado que pasaba de creer dominar los hechos, a convertirse en participante sumiso, en autómata de cuanto superaba su exclusivo dominio individual. El devenir histórico arrollaba así toda concepción clásica de la vida, toda vez que la criatura comenzaba a superar tanto en potencial como en intenciones los deseos de quienes la engendraron. Walter Benjamin, en este sentido, mencionará que

la técnica reproductiva desvincula lo reproducido del ámbito de la tradición. Al multiplicar las reproducciones pone su presencia masiva en el lugar de una presencia irrepetible (Benjamin: 1989: 22).

La devoradora relación de factores propia del conflicto bélico, adoptada ahora como sistema usual de vida, como urgencia por extraer el mayor potencial de toda fuente generatriz, incorporaba -o trataba al menos de lograrlo- al artista, al modelo de hombre considerado como iconoclasta ante los intereses venideros, como integrante de sus propias filas, pasando el poeta o el pensador, el custodio del espíritu, a ser una pieza más de la amplia cadena de montaje, a ser, también él, un trabajador.

Desde luego, las terribles y devastadoras fuerzas liberadas tras la Primera Guerra Mundial se perpetuaron sin problema logrando asegurar su ancla en un terreno propicio una vez que el equilibrio entre elementos regresivos y progresivos quedaba resuelto a favor de estos últimos -en lo referente a la autonomía del elemento técnico- posibilitando así la comprensión de la vida a modo de inmenso núcleo de comercio. La tecnificación masiva, asociada simbólicamente a la muerte del individuo, se desplazaría 
de inmediato con toda naturalidad hacia terrenos apenas hollados o, al menos, nunca antes dominados de tal modo por el reino de la cantidad. Terrenos, en lo concerniente al arte, que pasaban de comprenderse como templo o alejamiento incluso del mundo, a entenderse como un medio excelente de propaganda, de alcance inmediato y capaz de envolver en una retórica elocuente la voluntad de las masas.

Cuando Ernst Jünger, en su ensayo Sobre el dolor, indica que «la cantidad de asentimiento, de "público», está convirtiéndose en el factor decisivo de la política», de una organización sustentada por «unas masas de conformación cada vez más uniforme» (Jünger: 1995: 121), está afirmando de modo paralelo una parálisis, un distanciamiento de la vida respecto de las determinaciones tomadas por los individuos, comprendiendo la vida no como una serie de hechos o incluso de relaciones de hechos, sino como el espíritu que concede sentido, densidad, a dichos hechos. Así, se podría hablar de una preparación del conflicto bélico desde un enfoque artístico, posibilidad que Jünger capta de nuevo de manera diáfana cuando sugiere

la siguiente idea grotesca: que un importantísimo jefe de publicidad hubiera de preparar la propaganda para una guerra moderna y que para desencadenar la primera oleada de excitación tuviese a su disposición dos medios, a saber: el asesinato de Sarajevo y la violación de la neutralidad belga (Jünger: 1995: 107-108).

Evidentemente, esta hipótesis no deja de ser un juego, una fábula, pero precisamente por su cualidad especulativa resulta simbólica, que es al fin y al cabo lo que nos interesa y cuanto cobra valor real en un ámbito en principio estético.

Al realizar este comentario el escritor alemán aludirá, de manera casi explícita, al peligro de que arte y vida invadan sus diferentes canales de expresión. Ambos, desde luego, han de permanecer unidos, pero en un plano simbólico, no directo, en la medida en que dada la naturaleza del uno y la de la otra -del arte y de la política-, el primero resultará bastante susceptible de dejarse apropiar por manos interesadas, mientras que la segunda va a participar de unas obvias necesidades de controlar, de dominar cuanto atrae el imaginario de las masas. Una vez que acaece esta apropiación, el estado pasará a proyectarse por medio de una agresiva campańa de propaganda, mientras que la realización artística va a devenir en medio publicitario, elemento ideal de representación masiva y unitaria de aquello que, utilizando la terminología de Jünger, se puede considerar el «Espíritu del tiempo». En este aspecto se aprecia perfectamente el progresivo avance de los estados desde un plano ideológico a otro mercantil y servil; el traslado de la Europa de los Imperios a la de los comercios, pasando por el estrato intermedio representado por el estado tecnificado, totalitario, convertido en mecanismo reproductor, leviatán cuya asimilación a lo hasta aquí mencionado haría del dirigente el artista y del pueblo el material utilizado, el barro a ser torneado. 
Resulta evidente que no es tanto la imagen, sea de la naturaleza que sea, como el uso que se hace de la misma, cuanto confiere el grado de relevancia de su poder. El sistema propagandístico, brutal, demoledor, no tanto por la cantidad, superada con creces hoy en día, como por el impacto que en su momento pudo causar el violento salto desde un orden jerárquico consolidado en función de unos valores en declive, hacia una sociedad de masas, hacia un nueva organización de la realidad altamente tecnificada, resultó el medio ideal de alejamiento del individuo respecto de esa misma realidad. A partir de entonces, la idea de una experiencia comenzaba a sustituir a la experiencia en sí, toda vez que cuanto consolidaba aquélla, el valor interno de ese hecho, no nacía arraigado al interior del individuo, sino que se presentaba como caído del cielo, dejando el individuo de actuar por convicción personal para pasar a defender unos valores ajenos a todo instinto elemental.

La guerra de material, por otra parte, sintomático traslado desde lo cualitativo hacia lo cuantitativo, se extendería, de nuevo simbólicamente, a todos los ámbitos de la sociedad, sustituyéndose la elaboración, el desarrollo artesanal de las satisfacciones básicas del individuo, por una masificación desbordante y saturnina; sustituyéndose el arte por la mecanización del mismo; el espíritu puro, el desinterés propio de la actividad creativa, por una publicidad ávida de cifras. De este modo, el pueblo, comprendido como elemento trabajador en un estado de movilización total, vio con buenos ojos el resultado de la obra que había de realizar; no ya una catedral, por ejemplo, como ocurriese en el medievo, sino una inmensa maquinaria demoníaca, participando como abeja obrera en la construcción de su jaula de esperanzas pero desconociendo, para su perdición, la génesis y el fin de la elaboración de la misma.

La propaganda, de acuerdo con lo visto, accederá hasta el individuo a modo de elemento usurpador de realidad, de herramienta incitadora al deseo o al rechazo, pero también y de manera especial a modo de elemento despreocupadamente condicionante del juicio que finalmente uno acabará por hacerse del conjunto de los acontecimientos. En este aspecto esa misma propaganda no deja de ser un elemento simbólico, un medio de relación entre diferentes factores, en este caso entre dirigentes y masas -nos acercamos ya a la Europa del segundo tercio de siglo-, que nos permitirá observar de manera incluso demasiado lógica la cadena que lleva de la Europa de los Imperios a la Europa moderna, pasando por la Europa del tirano y del trabajador. Por todo ello nos aventuramos a decir que, desde cuanto comprendemos, resulta obvio el trasvase y el medio por el que se produjo este cambio, no así, evidentemente, el modo, una vez que resultó necesario un elemento intermediario, un catalizador -representado por un tirano dibujado con tintes fáusticos- entre el Imperio o el Emperador -representante de una altura sobrehumana-, y aquel colectivo provisto, tras el efecto liberador que supuso la Gran Guerra, de todos sus elementos primarios bullentes y descontrolados. El rol que cada uno de los elementos desempeñó en este esquema, continuando con 
el símil mencionado líneas atrás, resultaría asimilable al representado por el zángano, por las obreras y por una reina-estado cuyo trono sería trágicamente usurpado. La función que le deparaba la historia a este elemento intermediario era, a ojos del pueblo, la de víctima propiciatoria, función representada en todas las sociedades y religiones de la historia por el papel del sacrificado, consideración potenciada una vez que, como sabemos, jamás se contó con una sociedad tan tristemente mecanizada y alejada de su más consustancial y natural elemento, la realidad.

En efecto, el mecanismo propagandístico había logrado que el pueblo, artesano infatigable del estado total, viviese encerrado en su propia obra, en su mundo recreado pero irreal, en la burbuja de cristal en la que, en definitiva, vivía el artista inocentemente antes de la Gran Guerra. Cuanto le deparaba a Europa tras el conflicto de inicios de siglo no era la Segunda Guerra Mundial. La obstrucción que suponía el Antiguo Régimen había caído por su propio peso, sin duda. El nuevo estado necesitaba, ya lo indicamos, de un mediador entre la vieja Europa y lo que vendría a ser la nueva organización continental, de otro modo se correría el peligro de entrar en una serie de revoluciones permanentes entre el joven pueblo y los elementos aún vivos de la antigua organización Europea. Sin embargo, el fracaso de la Sociedad de Naciones y el horror de los totalitarismos condujeron sin remisión alguna hacia la masacre y el error de la Segunda Guerra Mundial. Veremos, a continuación, guiados por Jünger, el papel que la propaganda y su efecto de distanciamiento poseyó en el desarrollo de los hechos.

Jünger va a hablar de una segunda conciencia a la hora de hacer referencia a los métodos contemporáneos de control, entre ellos la fotografía, especie de mal de ojo una vez que ejerce un consabido afán de posesión correspondiente con su efecto paralizante, con la presentación de unos hechos de modo perfectamente definidos, exactos, desproveyendo al objeto del efecto de reverberación, de la radiación constitutiva de todo ser y fenómeno; en definitiva, de toda potencia espiritual. La citada parálisis conllevará, desde luego, una detención del razonamiento en la medida en que nos obliga a ver sólo realidad, sólo luz, privada de matices y sombras, donde debería observarse un elemento vivo poseedor de toda su fuerza primaria y, por lo tanto, proclive a desdibujar, a confundir los márgenes que separan el horror de la belleza. Únicamente con el tiempo, cuando la fotografía se fuese despojando más y más de su forma hierática, cuando cobrase plasticidad al permitir la entrada de elementos proclives al juego, al efecto artístico -en definitiva, sólo cuando comenzase a ser estética y con ello potencialmente ética-, se vería dotada de cualidades puramente creativas, liberadoras, posibilitando así el juicio crítico de quien la contemplaba en detrimento del hasta entonces imperante sentido interesado y unidireccional, cosificador. En un estudio sobre el pensamiento de Jünger, el filósofo Franco Volpi indicará que 
la determinación del carácter valorativamente neutro de las ciencias humanas y sociales -una posición íntimamente ligada al reconocimiento de su cientificidad- desvincula este saber de cualquier función orientadora y la desliga de los valores que, -conforme a otra concepción típicamente moderna- debe guiar la acción, la vida y la convivencia humana. El desarrollo de una cientificidad estricta entendida como neutralidad ante los valores trae consigo que la razón tradicional quede privada de su sustancia y resulte reducida a pura razón instrumental. Con la imposibilidad de lograr una orientación de la acción que sea racional y global, el ideal de la ciencia así construido pierde relevancia para la vida, pierde su significación vital (Volpi: 1996: 173).

En lo que a nosotros nos ocupa, dilucidamos aquí perfectamente una doble polaridad que observamos repetidamente en la obra de Jünger y encuentra su proyección tanto en el problema de la técnica como en los medios de propaganda modernos, un problema que concierne al constante pulso entre arte entendido como «impulso de juego», a la manera de Schiller, y una técnica comprendida como elemento reificador, usurpador del espíritu que pone al individuo en movimiento.

De acuerdo con esta última idea, la fotografía de propaganda no dejará de ser una variante más del infinito número de modos por los que el mundo fenoménico se nos presenta encorsetado bajo una naturaleza muerta, forma carente de efervescencia vital, desproveyéndonos a su vez de la posibilidad de entrar en diálogo con él, en definitiva, de realizarnos. Los medios por los que los enfrentamientos bélicos y, fuera de ellos, los discursos políticos, se presentaron ante la población hace ya un siglo, se vieron potenciados por un mayor abuso de elementos tecnificados y, consecuentemente, falseados. Por ello, no resulta justo hacer alusión exclusivamente a la fotografía como instrumento manipulador, sino que todo modelo de expresión, una vez despojado de su singularidad tornándose por tanto en propaganda, en artificio de masas, agotará su contenido al quedar enmarcado en unos límites restrictivos, opresivos, donde no hay cabida para el vuelo libre de la imaginación y sí, en cambio, para un discurso presentado ante el individuo como proyección abominable de un determinado órgano de poder. Resulta instructivo observar cómo, ya en época pretotalitaria, no sería el pueblo quien expresase su voz, su voz viva, a través de un líder determinado, sino que sería este último, identificando en extremo el término "autor» con el designado por la función de su cargo, «autoridad», quien realizaría sus deseos a través del material con el que contaba, el pueblo. La equiparación establecida aquí entre pueblo y material, claro está, obedece a la pérdida de cualidades expresivas que en estas condiciones el pueblo sufre, quedando reducido a elemento pasivo proclive a tomar por suyo cuanto le viene dado desde el exterior, desde la voz y el deseo del tirano.

La voracidad propia del desarrollo moderno, cuya encarnación más exacerbada en torno al periodo de entreguerras quedaría representada por el estado, resultaba absolutamente enemiga del desarrollo interno propuesto por Ernst Jünger y, desde luego, 
más si cabe, de la necesidad de expresión propia del escritor, cuya incontinencia, dado el componente de desafío y veracidad con que se manifestaría a lo largo de su vida, así como el peligroso marco en que hubo de desarrollarse, resultó más que incómoda para el Estado mayor alemán ya con anterioridad así como durante el desarrollo de la Segunda Guerra Mundial. Cuanto encontramos en Jünger es un amor incondicionado por toda expresión viva, aun cuando ésta resulte peligrosa e incluso destructora. En cambio, no dudará en tomar por sus mayores enemigos todos aquellos aspectos de la naturaleza capaces de separarle de la libre creación. En este aspecto Jünger se mostrará más coherente incluso que Goethe, personalidad afín al novelista tal y como observa Manfred Osten cuando hace referencia a una "contemporaneidad extemporánea» (Osten: 1996: 35) que reúne a ambas figuras más allá del tiempo. La creencia en un destino individual, la participación de un fatalismo homérico, ayudará a Jünger a enfrentarse con ánimos elevados a la adversidad, acudiendo como voluntario a la Primera Guerra Mundial al poco de cumplir la mayoría de edad y participando en la Segunda como capitán de un regimiento pese a su rechazo hacia el ansia aniquiladora que animaba a los dirigentes del Partido, pudiendo constatar, tal y como Goethe ya advirtiese, cómo los poderosos juegan con los débiles y, a su vez, los dioses hacen lo propio con los poderosos.

«El Espíritu del los tiempos» seguía ya en el segundo tercio de siglo una dirección que en nada compartiría Ernst Jünger, abismándose hacia un proceso de deshumanización completo en aras de un dominio técnico usurpador y enfermizo. Se llegaba así al punto en que «el hombre ha desarrollado fuerzas que ya no puede controlar» (Molinuevo: 1994: 166), el aprendiz de brujo. El descanso que uno halla mientras lee sus diarios de la Segunda Guerra Mundial, es el mismo que el buscado por el anacoreta alejado del mundo, aquel que -según refiere nuevamente Molinuevo- quedaría representado por la figura del emboscado en la obra del autor. Este emboscado será precisamente quien vive «en un tiempo distinto de los demás», en una «ambigua actualidad intemporal, propia de las existencias transitorias que sacan fuerzas de la amenaza» (Molinuevo: 1994: 14). Dominio, técnica o persuasión, conformarán elementos de intromisión para el recogimiento interno, casi contemplativo, que el escritor perpetuará incluso en el campo de batalla.

Que Jünger mantenga con la política una relación de distancia es algo que no ha de sorprendernos -menciona Luis Fraga-. La distancia (que es cosa distinta al desinterés) forma parte de su estilo, de su personal modo de ver o aprehender la realidad. Jünger, a través de la distancia, ve. Se trata, ante todo, de un autor visual que nos habla en imágenes, figuras, formas (Fraga: 2006: 78).

Por ello mismo, enfrentándose a su desinterés, su repulsa incluso hacia la fotografía, se dedicó en torno a los años treinta a la confección de una serie de fotolibros 
con el propósito de apuntalar las imágenes con su propio pensamiento, de avivar con su expresión una serie de fotografías que, enfrentadas unas con otras, delataban el carácter engañoso de un discurso histórico-político frente a la vivencia individual de los hechos, frente a la experiencia vivida, padecida más bien, por quienes hubieron de comprender de primera mano que nada se identificaba la realidad conocida, dada de modo objetivo y alejado -cómodo, en definitiva- desde los mecanismos de poder, con aquellas vivencias inhumanas desprovistas del parapeto de seguridad con que le llegan al público, al burgués.

De acuerdo con Jünger, los tiempos iban conduciendo irreparablemente hacia un estado donde, por una parte, se encontraba el burgués, masiva encarnación de la abeja zángana aludida anteriormente y, por otra parte, se hallaba el trabajador, entendido éste como individuo sacrificador de sus fuerzas, alejado de un estado óptimo de cosas, de una realidad favorable pero, sin embargo, capaz aún de sentir el torrente vital dentro de sí, de mantener animada la llama de lo propiamente humano; un individuo, en definitiva, entregado al sufrimiento una vez que la sociedad tecnificada ponía todo su armamento al servicio del bienestar de aquel burgués alejado por completo de la fuente de la vida, de toda alteración capaz de romper la sucesión monocorde de su existencia. El trabajador se presentaba para Ernst Jünger como aquel que, pese a las opresiones, permanecía con plenas aptitudes para disfrutar, acceder y embriagarse de los placeres ofrecidos por la naturaleza. El escritor, en su ensayo titulado precisamente El trabajador, reafirmará el valor de este hombre al considerar que

en la cercanía de la Muerte, de la Sangre y de la Tierra asume el espíritu unos rasgos más duros y se tińe de unos colores más intensos. La existencia se halla expuesta a mayores amenazas en todos sus estratos, hasta llegar a aquel género de hombre, casi caído ya en el olvido, frente al cual fracasan todas las regularidades económicas y que coloca a la vida ante la alternativa de perecer o de conquistar. Una actitud que quiera estar a la altura de estas decisiones tendrá que alcanzar, dentro de unas destrucciones cuyas dimensiones no son visibles todavía en su integridad, ese punto desde el cual resulta posible tener una sensación de libertad. (Jünger: 1990: 62).

De acuerdo con lo leído, no cabe comprender la figura del trabajador únicamente como el explotado sino como quien se mantiene cercano, ligado aún, al ombligo de la vida. Su rasgo esencial no será, por lo tanto, el que deba realizar una acción no deseada por él mismo, pues esto último lo determina en primer lugar un condicionamiento al que inevitablemente quedará expuesto, sino una particularidad que reside en el mantener su torrente vital aún vivo y despierto. Por este motivo, frente al encorsetamiento que supone y conlleva toda imagen definida, manejada mediante una violencia contraria a su esencia, el trabajador poseerá la cualidad de mantener inalterable su espíritu frente a todo tipo de bárbara imposición, convirtiéndose en consecuencia en elemento de riesgo 
para el poder. Este riesgo será asumido - en no pocas ocasiones aun a su pesar- a costa de dañar su vida, afanándose y viéndose obligado a adquirir experiencias primarias en detrimento de cuanto viene envuelto en bellos ropajes, becerro de oro que jamás podrá conquistar. Cuanto se presente ante el trabajador será un mundo más real si cabe pero mucho menos bello que aquel otro que recibe benévolamente el ciudadano cómodo, un ciudadano que no sospecha qué hay de engañoso en su incierta realidad. Para él, para este ciudadano modelo, estandarizado, se ofrecerán en sacrificio las guerras, pudiendo así nutrir sus apetitos de emociones siempre desde una prudente distancia. A él se sacrificarán vidas, vidas plenamente experimentadas como existencia. Esta secuencia de pérdida de plenitud vital arrastra de lejos y coincidirá quizás con aquella progresión expuesta por Hesíodo a la hora de aludir a las cinco edades del ser humano, desarrollo en constante decadencia. En cualquier caso, ya en su momento Talleyrand afirmó que únicamente sabían lo que era vivir todos aquellos que habían nacido antes de 1789, antes de una Revolución que permitió, por una parte, la liberación del pueblo y, a la larga, el endiosamiento del burgués, el apogeo con ello de su nihilismo consustancial como señor absoluto de nuestro mundo.

De todo lo expuesto y su implicación directa con el tema que nos concierne, queda un rechazo total hacia una imagen llegada hasta nosotros con ropajes de muerta, un alejamiento entre la realidad y el ser humano como consecuencia de la interposición de signos falsos, interesados, entregados al individuo como modelos desprovistos de dolor y de belleza, alegorías de un tipo de mentalidad afanada en la búsqueda de seguridades, ciega ante la otra cara de la naturaleza, aquella que requiere de víctimas con las que mantener el bienestar de quien puede pagárselo e incluso elevar aún más dicha bonhomía, pues el deseo no se conforma con cuanto ya posee, queriendo siempre más.

Frente a este rostro falso de la historia, aguarda la realidad, rica en símbolos y en verdades. Fácil resulta hoy realizar una lectura alegórica de las imágenes propagandísticas con que se vio abrumada Europa durante la primera mitad del siglo dejado atrás y ver a través de ellas una segunda realidad no tanto representativa sino simbólica. Fácil resulta observar en el rostro amable del tirano el gesto sonriente de la muerte, pues la distancia nos aporta claridad, sin embargo pocos supieron leer en el momento, tal y como hiciese Jünger, la falacia que se escondía detrás de toda palabra, de toda imagen que mostrando tan sólo belleza escondía unos fines macabros y enteramente funestos.

\section{BIBLIOGRAFÍA}

Benjamin, Walter; "La obra de arte en la época de su reproductibilidad técnica», en Discursos interrumpidos I, Taurus, Buenos Aires, 1989.

Fraga, Luis; «Ernst Jünger y su visión del poder», en Ernst Jünger y sus pronósticos 
del Tercer Milenio; Editorial Complutense, Madrid, 2006, pp. 73-109.

Jünger, Ernst; El trabajador. Dominio y figura; Tusquets, Barcelona, 1990.

Jünger, Ernst; Sobre el dolor. Seguido de La movilización total y Fuego y movimiento; Tusquets, Madrid, 1995.

Jünger, Ernst; El mundo transformado. El instante peligroso; Pre-Textos, Valencia, 2005.

Molinuevo, José Luis; La estética de lo originario en Jünger; Tecnos, Madrid, 1994.

Osten, Manfred; «Ernst Jünger y Johann Wolfgang von Goethe: Convergencias y divergencias» en Ernst Jünger y sus pronósticos del Tercer Milenio; Editorial Complutense, Madrid, 2006.

Volpi, Franco; «La razón práctica en medio de su depotenciación técnica», en Junto a Jünger, Cruce, Madrid, 1996. 